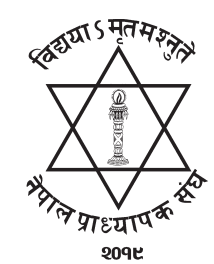

NJ: NUTA

\title{
Social Participation and Quality of life of Rural Elderly Living in Community Dwelling in Nepal
}

\author{
Mahendra Raj Joshi \\ Department of Population Studies, Kailali Multiple Campus, Far Western University, Nepal. \\ Email: drmahendrarajjoshi@gmail.com. ORCID: 0000-0002-8808-2869
}

\begin{abstract}
The concept of social participation integrates with the policy of active ageing along with health and security. It encourages and advocates the productive engagement of elderly and acknowledges their potential contribution in the society. The main objective of this paper is to explore the status of social participation and its influence on their quality of life of older people living in community dwelling in Nepal. A cross-sectional community-based survey was carried out (November-December 2017) among 547 randomly selected 60 years and older people living in community dwelling. Quality of life (QOL) was measured by using the World Health Organization Quality of Life-abbreviated scale and social participation was measured by asking direct questions related to their participation in publing meeting, and perception about social relations in last one year. Descriptive technique was used to analyze the data. One way ANOVA was performed to explain the significance of differentials in quality of life and its dimension among older people.vThe findings shows majority (52.9\%) of males and less than half of females $(37.9 \% \%)$ who have attended any types of publing in last one year. This study found $Q O L$ score of Nepalese elderly was 12.92. It shows quality of life of Nepalese elderly was moderate level (with in the range of 4-20 scales). The mean scores of overall QOL index of elderly people who have attended public meeting was observed significantly higher $(M=13.72)$ compared to those who did not attend of any public meeting $(M=12.29)$. Elderly social participation have significantly better quality of life in Nepal. This suggests the need to improve the frequency of participation of elderly people to their community which provides them opportunities to interact more with their physical as well as social environment that consequently improved their overall $Q O L$.
\end{abstract}

Key Words: Ageing, Living arrangements, Older adult, Quality of life, Social participation

\section{Introduction}

The phenomenon of population ageing is the major emerging demographic concern of the 21 st century. Increasing life expectancy and higher expectations of a good quality of life in old age highlight the importance of an active lifestyle in later life. Social participation plays an important role in determining quality of life of elderly people. Social participation lies on the foundation of social network that are developed through shared activities, shared culture, history or circumstances. WHO (2002) active ageing framework also acknowledges the role of community participation as one of the three pillars 
(Health, security, and community participation) that promote active ageing amongst older people. United Nations principles for the older persons interdependence, participation, care, self-fulfillment, and dignity guide this framework. As ageing is often associated with a reduced ability to engage in the community resulting in social isolation and exclusion, it has serious consequences on the physical and psychological well-being and quality of life (QOL). Participation facilitates a productive contribution of the elderly in society. Disengagement theory states that the aged tend to withdraw themselves from social interactions and it is a natural and universal process (Barren JB \& Cunningham W, 1985). In the Nepalese context, 'Ashramas' theory espouses the same. Sanyasa is the stage of life for total disengagement from society. But, according to Activity theory by Havighusrt, individuals need to keep themselves active to enjoy the active ageing, which is the core philosophy of active ageing (Barren JB \& Cunningham W, 1985).

Older people in Nepal especially in rural areas are prone to social isolation and exclusion due to lack of social participation. Older people's participation in social networks is a significant component of wellbeing. Many older people are socially active and participate in culture, recreational and other activities. Social contact with friends and relatives outside the home declined significantly with age and it has serious consequences an older people's participation in community activities and events. The definition of 'participation' brings in the concept of involvement i.e., incorporate taking part, being included or engaged in an area of life, being accepted, or having access to needed resources. Prohaska, Anderson and Binstock (2012) noted that the term social participation is commonly used to refer to one's participation in the activities of a social group. The term has been defined by Avison, McLeod and Pescosolido (2007) as "the extent to which an individual participates in a broad range of social roles and relationships." and by Zhang, Jiang, and Carroll as "the commitment of a member to stay in the group and interact with other members".

Enhancing the social participation of the elderly is a key factor in achieving the goal of successful ageing. Bennett (2002) considered three aspects of social ageing, one of which included social participation with the social world. Studies have highlighted the significance and multiple benefits of social participation of elderly but, impact of social participation on older people's quality of life in Nepalese context is under-researched. This knowledge gap is critical as it can contribute in guiding policymakers and social development professionals on the creation of opportunities to allow older adults increase or maintain their social engagement levels, and consequently, enjoy active and successful ageing. Reasons for the emphasis on social participation in old age are mostly related to evidence that being socially active is associated with well-being, quality of life and lower risk of morbidity and mortality (Pynnönen, Törmäkangas, Heikkinen, Rantanen, \& Lyyra, 2012; Ponce, Rosas, \& Lorca, 2014; Pinto \& Neri, 2017). Furthermore, Douglas, Georgiou, and Westbrook (2017) argued that the world population ages, more attention is being paid to supporting older adults to remain connected to and contributing members of their communities. Therefore, in this study, an attempt was made to understand how social participation activities vary among the rural older adult who were living in community dwelling in Nepal. Specifically, the emphasis of this study was on the status of social participation among older adult and its influence on their quality of life in who were living in community dwelling in Nepal. 


\section{Methods and Materials}

This is a cross sectional study carried out in November-December, 2017. For this study two Village Development Committees (VDCs) of Kailali district, western part of Nepal were chosen. Each VDC has nine wards (the lowest-level political unit). The VDCs in this study were choosen as they comprise the highest proportion of elderly population in the district. Total sample size for this study was determined through Yamane formula (Yamane, 1967). Multi stage sampling design was adopted for this study. At the first stage, two VDCs named (Hasuliya and Basauti (now renamed as Kailari Rural municipality) of Kailali districts were chosen. Second, all the 18 wards of selected VDCs were considered as a sampling cluster. At the last stage, 22 households from each cluster was fixed. Systematic random sampling method was used for the selection of 22 households from each cluster. All the individuals 60 years and above of selected household were included as the respondents. People having mental health problem as reported by family members were excluded. Thus the total sample size for this analysis was 547 older adults. Face to face interview was used to collect the information. Verbal informed consent was obtained from participants prior to the interview. Data were collected through personal interviews by trained interviewers in participants' home with privacy.

\section{Measurement of variables}

Social participation was measured asking a direct question "The first was" How often in the last 12 months have you attended any public meeting in which there was discussion of local community or political affair?" with categorical response never, once or twice per year, once or twice per month, and once or twice per week. The WHOQOL-BREF questionnaire (1998) was used to assess the QOL of participants. The WHOQOL-BREF consists of 26 items with the response options ranging from 1 (very dissatisfied/very poor) to 5 (very satisfied/very good). The first two items general QOL and general satisfaction with health were not included in the overall QOL index. The remaining 24 items assessed four domains: physical, psychological, social, and environmental. The physical domain (7 items) assessed activities of daily life, including dependence on medicine, energy and fatigue, mobility, and work capacity. The psychological domain (6 items) assessed positive and negative feelings, including self-esteem, bodily image and appearance. The social domain ( 3 items) assessed personal relationship, social support and sexual activity. The environmental domain ( 8 items) included questions related to financial resources, freedom, safety and security, health and social care, physical and home, and transport. Finally, an overall QOL Index was designed exclusively for this study by taking the means of all four domains of QOL i.e. Physical health, psychological state, social relations, and environment. The potential score of the index ranges between 4- 20 scale. It is interpreted that 4 indicates the 'worst' and 20 indicates the 'best' level of quality of life of elderly people.

The WHOQOL-BREF has been validated for assessing QOL in a range of settings and used to assess QOL of older adults by a number of studies. The WHOQOL-BREF has been used among older adults in Nepal (Sapkota, Sedhain, Rai, 2013). with past application of the Nepalese version demonstrating high reliability (Mishra, Sharma, Bhandari, Bhochhibhoya, Thapa, 2015). The WHOQOL-BREF scale in this study demonstrated high internal consistency with a Cronbach's alpha coefficient of 0.79 . 


\section{Findings}

Participation in public meetings

Elderly people in Nepal especially in rural areas are prone to social isolation and exclusion due to lack of social capital. Elderly peoples' participation in social networks is a significant component of well-being. Frequency of attending any group, club, society, or organizational meetings ensures active participation of elderly people in social matters and helps them feel independent and capable of taking decisions. Generally, the types of the public meetings which were organized in the study area included: Aama Samuha (Mother's club), Kishan Samuha (Farmer's club), Tole Sudhar Samiti (Neighbour's club) and elderly club.

Table 1. Frequency of participation in public meetings in last one year by the elderly people

\begin{tabular}{|c|c|c|c|c|c|c|}
\hline \multirow{2}{*}{$\begin{array}{l}\text { Demographic } \\
\text { variables }\end{array}$} & \multicolumn{4}{|c|}{ Participation in Public Meetings } & \multirow[b]{2}{*}{$\mathrm{N}$} & \multirow[b]{2}{*}{$\mathrm{P}$} \\
\hline & Never & $\begin{array}{r}\text { Once } \\
\text { or } \\
\text { twice } \\
\text { per } \\
\text { year }\end{array}$ & $\begin{array}{r}\text { Once } \\
\text { or } \\
\text { twice } \\
\text { per } \\
\text { month }\end{array}$ & $\begin{array}{r}\text { Once } \\
\text { or } \\
\text { twice } \\
\text { per } \\
\text { week }\end{array}$ & & \\
\hline \multicolumn{7}{|l|}{ Sex } \\
\hline Male & 47.1 & 27.6 & 21.8 & 3.6 & 225 & \multirow[t]{2}{*}{$<0.001$} \\
\hline Female & 62.1 & 2.7 & 24.8 & 0.3 & 322 & \\
\hline \multicolumn{7}{|l|}{ Age group } \\
\hline $60-74$ & 43.7 & 13.3 & 30.9 & 2.1 & 382 & \multirow[t]{2}{*}{$<0.001$} \\
\hline $75+$ & 84.2 & 8.5 & 6.7 & 0.6 & 165 & \\
\hline \multicolumn{7}{|l|}{ Caste/ethnicity } \\
\hline Hill caste & 56.4 & 17.9 & 19.2 & 6.4 & 78 & \multirow[t]{4}{*}{$<0.001$} \\
\hline Hill Janjati & 0.0 & 67.7 & 33.3 & 0.0 & 6 & \\
\hline Tharu & 4.4 & 17.8 & 19.8 & 1.0 & 409 & \\
\hline Hill dalit & 20.4 & 22.4 & 57.4 & 0.0 & 54 & \\
\hline Total & 55.9 & 18.8 & 23.6 & 1.6 & 547 & \\
\hline
\end{tabular}

Note:. Hill Caste includes Hill Bhraman, Chhetri and Thakuri; Hill Janajati include Magar and Gurung; Hill Dalit incudes Kami, Damai/Dholi, Sarki, Sonar, Lohar, Tamata and Badi caste group.

All the respondents were asked about the frequency of attending public meetings held in their community. Over half of respondents (55.9\%) reported that they never attended any public meetings in last one year. An almost negligible proportion (1.6\%) of respondents attended public meetings once or twice per week in last one year.

The data on sex of the respondents reflect that majority of female respondents $(62.1 \%)$ reported that they have never attended any public meeting in the last one year while the corresponding figure for male respondents was less than half $(47.1 \%)$. This is statistically significant which suggested that the practice of participation in public meeting was significantly different between the genders.

Caste/ethnic group wise data shows that majority of Tharu respondents $(61.4 \%)$ reported that they have never attended public meeting in the last one year while the corresponding figure for Hill 
Caste group respondents was over half (56.4\%). On the other hand, majority of respondents of Hill Janajati caste/ethnic group $(66.7 \%)$ reported that they have attended a public meeting once a year in the last one year (Table 1). This is statistically significant. This means the frequency and practice of participation in public meeting is significantly different according to caste/ethnic group of respondents.

\section{Social Relations}

Nearly two-third of the respondents $(65.3 \%)$ satisfied, nearly one-third of the total respondents $(32.0 \%)$ took a neutral position and a few $(2.8 \%)$ respondents were dissatisfied with their personal relationships (relationships with children, family and friends). More male (68.9\%) than female (62.7\%) respondents were satisfied with their personal relationship. This difference was statistically significant.

Table 2: Frequency of perception towards social relations in last one year by the elderly people

\begin{tabular}{|c|c|c|c|}
\hline \multicolumn{4}{|c|}{ Social Relations Domain } \\
\hline Satisfaction with personal relationship & Male & Female & Total \\
\hline Dissatisfied & 1.8 & 3.4 & 2.8 \\
\hline Neither dissatisfied nor satisfied & 29.3 & 33.9 & 32.0 \\
\hline Satisfied & 68.9 & 62.7 & 65.3 \\
\hline $\mathbf{N}$ & 225 & 322 & 547 \\
\hline \multicolumn{4}{|c|}{$\mathrm{P}<0.05$} \\
\hline \multicolumn{4}{|l|}{ Sex life } \\
\hline Dissatisfied & 2.7 & 6.9 & 4.6 \\
\hline Neither dissatisfied nor satisfied & 28.0 & 21.4 & 24.9 \\
\hline Satisfied & 69.3 & 71.7 & 70.5 \\
\hline $\mathbf{N}$ & 186 & 156 & 345 \\
\hline \multicolumn{4}{|c|}{$\mathrm{P}>0.05$} \\
\hline \multicolumn{4}{|l|}{ Satisfaction with support from friends } \\
\hline Dissatisfied & 2.7 & 3.4 & 3.1 \\
\hline Neither dissatisfied nor satisfied & 48.9 & 57.8 & 54.1 \\
\hline Satisfied & 48.5 & 38.8 & 42.8 \\
\hline \multicolumn{4}{|c|}{$\mathrm{P}=0.05$} \\
\hline $\mathbf{N}$ & 225 & 322 & 547 \\
\hline
\end{tabular}

Majority of those who responded to their satisfaction with sex life, reported to be satisfied with it, however as only about a two-thirds of the total respondents responded to this question, this facet was deleted from this domain due to less than 80 per cent responses. A little over than twofifth of the total respondents (42.8\%) reported satisfaction with support from friends. Over half of the respondents (54.1\%) reported neither satisfaction nor dissatisfaction with support from friends as majority of them reported having no friends, hence support from them was irrelevant in that context. More male respondents (48.5\%) than female respondents $(38.8 \%)$ satisfied from friends.

\section{Impact of Social Participation on Quality of Life of Elderly People}

The mean scores of various domains and overall QOL index were calculated to understand the impact of social participation on elderly person's QOL. It was observed that elderly people participating in public meeting had low mean scores in all the domains of QOL. Mean scores of all domains was observed significant. The highest mean scores was observed in the social relations domain 
of elderly people participating in public meeting $(\mathrm{M}=14.65)$ and mean score was found the lowest for environmental domain of the elderly people participating in public meeting $(\mathrm{M}=11.46)$.

Table 3: Impact of social participation on dimensions of quality of life of elderly people

\begin{tabular}{|l|c|c|c|c|}
\hline $\begin{array}{l}\text { Dimensions of } \\
\text { QOL (Mean } \\
\text { Score) }\end{array}$ & $\begin{array}{c}\text { Ever } \\
\text { participation of } \\
\text { public meeting }\end{array}$ & $\begin{array}{c}\text { Never } \\
\text { participation of } \\
\text { public meeting }\end{array}$ & Total & P \\
\hline Physical health & 14.62 & 12.80 & 13.69 & $<0.001$ \\
\hline $\begin{array}{l}\text { P sy ch olog ic al } \\
\text { state }\end{array}$ & 13.96 & 12.22 & 12.99 & $<0.001$ \\
\hline Social relations & 14.65 & 13.73 & 14.14 & $<0.001$ \\
\hline Environmental & 11.46 & 10.43 & 10.88 & $<0.001$ \\
\hline $\begin{array}{l}\text { Overall QOL } \\
\text { Index }\end{array}$ & 13.72 & 12.29 & 12.92 & $<0.001$ \\
\hline
\end{tabular}

The mean scores of overall QOL index of elderly people who had never participated in public meeting was observed low $(M=12.29)$ compared to those who did participate in public meeting $(\mathrm{M}=$ 13.72). The result was observed significant. This indicates that older people who had never participated any public meeting have significantly low psychological health, hampered social relations, low mean scores for environmental domain, as well as poor overall quality of life as compared to those who had ever participated in public meeting.

\section{Discussions}

This is the first study to our knowledge that assess the quality of life of Nepalese elderly using internationally valid instruments. There are very little study carried out on the social participation and quality of life of elderly in Nepal and earlier studies only trying to focus on some different aspects of elderly such as: loneliness (Chalise, 2010) depression (Chalise \& Rai, 2013), functional disability (Chalise, Kai, \& Saito, 2007), self-reported health (Chalise, Kai, \& Saito,2007), sleep quality (Chalise \& Lamsal, 2017), Abuse (Chalise \& Basnet, 2017), health and social care need assessment (Central Department of Population Studies/TU, 2012), Perceived QOL (Joshi, Chalise, \& Chalise, 2019), living arrangement and QOL (Joshi, 2019), physical and mental health (Joshi, 2018), Socio-economic status (Joshi, 2020a), factors determining QOL (Joshi, 2020b). This study found that, less than half of the total respondents (44.1\%) reported to have participate in publing meeting in last one year. Previous study shows social participation rate of elderly people ranges from $12.7 \%$ (Nidhi, 2016) to $64.2 \%$ (Singh, 2019) among community living elderly. This vast difference should be due to the differences is instrument used to assess the social participation of elderly. In this study mainly participation in public meeting was focused and social participation was assessed focusing the period of last one year but other studies focused on participation in public meeting, religious programmeand particicipation in elderly and time duration was last one month to one year. This study found that social participation practices found varies according to gender difference. For instance, this study found that social participation practice was reported higher for male elderly (53.9\%) compared to female elderly (37.9\%). This found quite similar with the study of Singh (2019) found that social participation of male elderly was higher (68.2\%) compared to female elderly (40.0\%). 
This study found QOL score of Nepalese elderly was 12.92. It shows quality of life of Nepalese elderly was moderate level (with in the range of 4-20 scales). This index observed near about other similar types of studies conducted at different part of India at different time period. In this context, Gupta (2016) conducted a study in Navi Mumbai (India) in urban areas on elderly women and found that the overall QOL index was 13.50 and the another types of study also conducted by Dongre and Deshmukh (2012) in rural areas of India on elderly men and women and the overall QOL index was observed 12.92 for elderly people. These studies have used similar tools to assess quality of life of elderly people.

This study found that social participation of elderly people has significant positive impact on quality of life of elderly people. For instance, the mean scores of overall QOL index of elderly who have participated in public meeting was observed higher $(\mathrm{M}=13.72)$ compared to those who never participated in public meeting $(M=12.29)$. This is quiet similar to the findings from the study conducted by Gupta (2016) in Navi Mumbai (India). Gupta (2016) found that the mean scores for overall QOL of older women participating in public meeting was found higher $(\mathrm{M}=13.76)$ compared to those who have never participated in public meeting in the last one year $(M=12.27)$. In the same line of philosophy, Active ageing advocates the continued participation of the elderly to enhance their well-being.

\section{Limitations of the study}

This study was conducted on selected households of rural area of Kailali district; so the generalizability is limited. The cross-sectional nature of the study has adopted simple statistical tools such as frequency, percentage, mean etc. Most part of the research is based on descriptive approach. The study has used the responses of elderly themselves to understand their social participation and perception towards quality of life.

\section{Conclusions}

This study found the low social participation practice of elderly people. Majority of the respondents have never participated in any public meeting in last one year. Quality of life of Nepalese elderly is also found moderate level. Further social participation of elderly has significant positive impact on elderly people's overall QOL. Hence, policy makers and programme managers need to prioritize working at societal level in order to improve social or community participation of elderly people to prevent isolation and improving their QOL.

\section{Declarations}

\section{Ethical consent to participate}

No applicable

Consent to publish

yes

\section{Competing interests}

The authors declare that we have no competing interests.

\section{Funding}

Not applicable 


\section{Acknowledgements}

It is the researcher's pleasure to thank the respondents for their cooperation during the field study. The researcher is also grateful to Dr Padma Prasad Khatiwada and Dr. Hom Nath Chalise for providing him with important feedback to improve this research study.

\section{References}

Barren JB, \& Cunningham W. (1985). Research on the psychology of ageing: principles: Concepts and theory. In J. E. Birren \& K. W. Schaie (Eds.), Handbook of psychology of ageing. New York: Van Nostrand Reinhold.

Bennett KM. (2002). Low level social engagement as a precursor of mortality among people in later life. Age and Ageing, 31(3): 165-168.

Central Department of Population Studies/Tribhuvan University (CDPS/TU). (2012). Health and social care need assessment of elderly. Kathamndu: Central Department of Population Studies, Ageing Nepal, United Nations Population Fund.

Chalise HN, \& Lamsal U. (2017).Walking and sleep quality of Nepalese older adults living in briddashram. Journal of Gerontology and Geriatric Med., 3: 1-5.

Chalise HN, \& Brightman JD. (2006). Ageing trends: Population Ageing in Nepal. Journal of Geriatrics and Gerontology. Available at https://doi.org/10.1111/j.1447-0594.2006.00347.x.

Chalise HN, \& Paudel BR. (2020). Dental and eye problem of Nepali older adults living in old age home. Journal of Health Care and Research. Available at: https://www.researchgate.net/ publication/340377875. DOI: 10.36502/2020/hcr.6155.

Chalise HN, \& Rai SL. (2013). Prevalence and correlates of depression among Nepalese Rai older adults. Journal of Gerontology and Geriatric Research, 2: 130-135. DOI:10.4172/21677182.1000130 .

Chalise HN, \& Basnet M. (2017). Abuse of older adults residing in the community of Nepal. International Journal of Gerontology and Geriatric Research,6: 415-424. DOI: 10.4172/216 7-7182.1000415.

Chalise HN, Kai I, \& Saito T. (2007). Significant variables of self-reported health: A study of older adults from a developing country like Nepal. Bio-Science Trends, 1: 102-107.

Chalise HN. (2010). Social support and subjective well-being of Nepalese older adults. Asian Social Work and Policy Review, 4: 1-25.

Chalise HN. (2017). Abuse of the elderly: A neglected issues in developing countries. Jacobs Journal of Gerontology, 3 (1): 024.

Dongre AR, \& Deshmukh PR. (2012). Social determinants of quality of elderly life in rural setting of India. Indian Journal of Palliative Care, 18 (3): 181-189.

Douglas H, Georgiou A, \& Westbrook J. (2017). Social participation as an indicator of successful aging: an overview of concepts and their associations with health. Australian Health Review, 41(4): 455-462.

Gupta N. (2016). Social Capital, Community Participation and Quality of Life: A Case of older women from urban setting in India. Journal of Madras School of Social Work, 1(2): 25-48.

Joshi MR, Chalise HN, \& Khatiwada PP. (2018). Quality of Life of Nepalese Elderly Living in Rural Nepal. J Gerontol Geriatr Res,7: 484, doi:10.4172/2167-7182.1000484.

NUTA JOURNAL, 7 (1 \& 2), 2020 : ISSN: 2616 - 017x 
Joshi MR. (2018). Physical and mental health status of elderly people in urban setting in Nepal. Indian Journal of Gerontology. 32 (4): 382-393.

Joshi MR. (2019). Living arrangements and quality of life of Nepalese elderly in rural Nepal. Indian Journal of Gerontology. 32 (2): 178-197.

Joshi MR. (2020a) Socio-economic status of elderly people in rural setting of Nepal. Journal of Geriatric Care and Research, 7(1): 36-42.

Joshi MR (2020b) Factors Determining Quality of Life of Elderly People in Rural Nepal. J Gerontol Geriatr Res, 9: 510. doi: 10.35248/2167- 0374.20.9.510

Mishra SR, Sharma A, Bhandari PM, Bhochhibhoya S, Thapa K. (2015). Depression and Health-Related Quality of Life among Patients with Type 2 Diabetes Mellitus: A Cross-Sectional Study in Nepal. PLOS ONE, 10 (11): e0141385. doi: https://doi.org/10.1371/journal.pone.0141385.

Pinto JM, \& Neri, AL. (2017). Factors related to low social participation in older adults: findings from the Fibra study, Brazil. Cadernos Saúde Coletiva, 25(3): 286-293.

Ponce MSH, Rosas RPE, \& Lorca MBF. (2014). Social capital, social participation and life satisfaction among Chilean older adults. Revista de saude publica, 48: 739-749.

Pynnönen K, Törmäkangas T, Heikkinen RL., Rantanen T, \& Lyyra TM. (2012). Does social activity decrease risk for institutionalization and mortality in older people? Journals of Gerontology Series B: Psychological Sciences and Social Sciences, 67(6): 765-774.

Sapkota A, Sedhain A, \& Rai MK. (2013). Quality of life of adult clients on renal replacement therapies in Nepal. J Ren Care, 39(4): 228-235. doi: https://doi.org/10.1111/j.1755-6686.2013.12021.x.

Singh V. (2019). Social participation and its determinants among the urban elderly (An unpublished Ph.D. Dissertation). School of Social Work Tata Institute of Social Sciences, Mumbai.

Smith A. (2001). Defining quality of life. Ageing and Society, 24 (5): 657- 674.

Prohaska TR, Anderson LA, \& Binstock RH. (2012). Public Health for an Aging Society. Retrieved from https://jhupbooks.press.jhu.edu/title/public-health-aging-society.

United Nations. (1991). Ageing and urbanization. New York: Department of Economic and Social Affairs, Population division, United Nations Secretariat.

Avision WR, McLeod JD, \& Pescosolido BA. (2007). Mental Health, Social Mirror. Retrieved from https://www.springer.com/gp/book/9780387363196.

World Health Organization (WHO). (2002). Active ageing policy framework. Geneva: Author. Retrived from http://www.who.int/ msa/mnh/mhp/ql1.htm. (Accessed on 28 February 2016).

World Health Organization Quality of Life Group (WHOQOL-Group) (1998). WHOQOLUser manual. Geneva: Author. Available at:http://www.who.int/ msa/mnh/mhp/q11.htm.

Yamane T. (1967). Statistics: An introductory analysis. New York: Harper and Row.

Zhang S, Jiang H, \& Carroll JM. (2011). Integrating online and offline community through Facebook. International Conference on Collaboration Technologies and Systems (CTS):569-578. doi: 10.1109/CTS.2011.5928738. 